\title{
Wollastonite to hinder growth of Aspergillus niger fungus on cotton textile
}

\author{
HAMID R. TAGHIYARI ${ }^{1}$, REZA MAJIDINAJAFABADI ${ }^{2}$ and REZA VAHIDZADEH ${ }^{2}$
}

\author{
${ }^{1}$ Wood Science and Technology Department, Faculty of Materials Engineering and New Technologies, \\ Shahid Rajaee Teacher Training University, Lavizan, 22970021 Tehran, Iran \\ ${ }^{2}$ Department of Restoration, Islamic Azad University, Central Tehran Branch/IAU - CTB, \\ Poonak Square, Ashrafi Esfehani Avenue, 9399807079 Tehran, Iran
}

Manuscript received on November 15, 2017; accepted for publication on December 20, 2017

\begin{abstract}
Effects of Aspergillus niger was investigated on the strength of cotton textile specimens impregnated with nano-wollastonite, and then compared with normal specimens. Cotton strips were cut and prepared in warp and wept directions according to the standard specifications ASTM D-5035. Results showed that incubation of $A$. niger on specimens for three months resulted in a significant decrease in tensile stress as well as weight mass change in both directions. Impregnating specimens with NW ameliorated the negative effects of fungal attack on tensile stress to a considerable extent. Moreover, weight change was significantly decreased. It is concluded that NW positively protect cotton textile against $\mathrm{A}$. nigra; the ultimate NW-content should be studied in complimentary studies.
\end{abstract}

Key words: biological resistance, cotton fabric, fungal degradation, mineral materials, textile, wollastonite.

\section{INTRODUCTION}

Different fungi spores are suspended in the air and are moved easily by air. This puts precious materials made from cellulosic materials at great risk of contamination and disintegration (Grace et al. 2017, Tanny et al. 2017, Tupciauskas et al. 2017). Many biological materials are vulnerable to ordinary fungi, being deteriorated by them (Seephueak et al. 2018). Cellulose and lignocellulose materials are amongst the materials that can be degraded by different fungi (Schmidt 2006, 2007, Abdel-Kareem 2010a, b, Maresi et al. 2013).

The main ingredient of cotton textiles is cellulose, a bio-polymer. This makes cotton textiles

Correspondence to: Hamid Reza Taghiyari

E-mail: htaghiyari@yahoo.com vulnerable to a wide range of different fungi, including Aspergillus, Penicillium, Chaetomium, Trichoderms, and Alternaria species (AbdelKareem 2010a). Exposure of historical objects, including papers, textiles, and wood, to deteriorating fungi is inevitable. Therefore, different polymers, fungicides, and nano-materials have so far been used to increase biological resistance of the materials to different fungi (Abdel-Kareem 2010a). Abdel-Kareem (2010b) treated textile samples with four polymers mixed with two kinds of fungicide. The samples were exposed to some dominant fungi isolated from ancient Egyptian textiles. The results of this study showed increase in the durability of the tested textiles; moreover, the textiles were reinforced. 
Cellulosic materials are vulnerable to different wood-deteriorating fungi and molds (Elaieb et al. 2017, Morias et al. 2018). Metal and mineral nano-materials have also been used to improve biological resistance of wood and wood composites to different fungi (Karimi et al. 2013, Taghiyari et al. 2014a, b, Bari et al. 2015, 2017, Taghiyari et al. 2013, 2015), and to improve many properties in different materials (Pethig 2017, Sandeep et al. 2017). Nano-zincoxide and nano-copper cannot be recommended as a fungicide for historical textiles due to their health problems to human though they have demonstrated high efficacy against Trametes versicolor fungus (Taghiyari et al. 2015). Therefore, attention was drawn to some other materials with lower hazard to human health (Taghiyari et al. 2014a, b). Wollastonite is a calcium-silicate-based mineral that has been reported to have no proven hazards to human health (Huuskonen et al. 1983a, b, Maxim and McConnell 2005). Experiments showed its high efficacy to different wood and paper deteriorating fungi, including Aspergillus niger (Taghiyari et al. 2014a-c).

A recent study illustrated that wollastonite nano-fibers were effective in hindering the growth of Aspergillus niger on historical papers (Taghiyari et al. 2014c). However, authors came across little or no study on the exposure of NW-treated cotton textile to any fungi. In this connection, cotton textile may react similarly or differently as regard to wood, wood composites, and even papers in which cellulose has a different structure. The present study, therefore, focused on possible improvement in biological resistance of cotton textile caused by NW treatment, against Aspergillus niger, as a dominant fungus in Moghadam Museum of University of Tehran.

\section{MATERIALS AND METHODS}

\section{SPECIMEN PREPARATION}

Iranian cotton fabric was purchased from Tehran Central Bazaar. Separate sets of strips were cut in the longitudinal (warp) and transverse (wept) directions of the cotton fabric according to the standard specifications ASTM D-5035. Dimensions of both warp and wept strips were $80 \times 30 \mathrm{~mm}$. Threads were removed from both sides of all warp and wept strips to produce final width of 20 mm, leaving fringes on both width sides (Fig. 1a, b). Strips of both warp and wept directions were randomly divided into three main groups of control (C), fungus-exposed (FE), and nanowollastoniteimpregnated fungus-exposed (NW-FE) specimens. Ten replications were produced for each of the groups; totally, 60 specimens were cut and prepared.

The size range of wollastonite nanofibers in the present project was $30-110 \mathrm{~nm}$. Specifications of wollastonite compounds and formulations are presented in Table I. Previous studies showed that NW with $20 \%$ concentration demonstrated optimum hindering effect on fungal growth (Taghiyari et al. 2014b, c). Therefore, 20\%-NWsuspension was prepared for immersion of the cotton strips. The NW-impregnated specimens were hanged to dry for four weeks before being exposed to the experimental fungus along with the control specimens.

\section{FUNGAL EXPOSURE}

Aspergillus niger (van Tieghem) is a common fungus species of the genus Aspergillus that belongs to Ascomycota. It is the cause of a disease called black mold and is considered a common contaminant of different food stuff, including fruits, vegetables, and cellulosic materials (Alexopoulos et al. 1996). The cotton fabric specimens were dried, at $103 \pm 2^{\circ} \mathrm{C}$ for $24 \mathrm{~h}$ in a hot air oven, and weighted before being exposed to the test fungus for three 


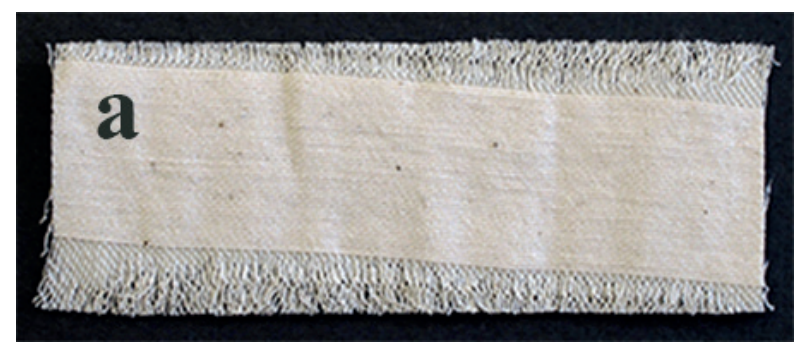

Figure 1 - Photographs of warp (a) and wept (b) control samples.

TABLE I

Compounds of the nano-wollastonite gel used for treatment purpose (Taghiyari et al. 2014a-c).

\begin{tabular}{cc}
\hline $\begin{array}{c}\text { Nano-wollastonite } \\
\text { compounds }\end{array}$ & Mixing ratio by mass (\%) \\
\hline $\mathrm{CaO}$ & 39.77 \\
$\mathrm{SiO}_{2}$ & 46.96 \\
$\mathrm{Al}_{2} \mathrm{O}_{3}$ & 3.95 \\
$\mathrm{Fe}_{2} \mathrm{O}_{3}$ & 2.79 \\
$\mathrm{TiO}_{2}$ & 0.22 \\
$\mathrm{~K}_{2} \mathrm{O}$ & 0.04 \\
$\mathrm{MgO}$ & 1.39 \\
$\mathrm{Na}_{2} \mathrm{O}$ & 0.16 \\
$\mathrm{SO}_{3}$ & 0.05 \\
$\mathrm{Water}$ & 4.67 \\
\hline
\end{tabular}

months in Petri dishes. Once the incubation period was passed, they were again weighted to measure weight change. The incubation process was carried out at the National Library and Archives of I. R. of Iran under $25 \pm 1^{\circ} \mathrm{C}$ and $45 \pm 2 \%$ relative humidity on Sabouraud's agar. It is to be noted that $A$. niger generally needs higher relative humidity and lower temperature for ultimate damage; however, in the present study, the deteriorating effect of the fungus under real conditions was the ultimate target. Once the incubation period passed, mycelia were removed from the specimens; care was taken not to disturb the textile texture. The specimens were again dried at $103 \pm 2^{\circ} \mathrm{C}$ for $24 \mathrm{~h}$ and weighed to determine the fungal mass change using Equation No. 1:

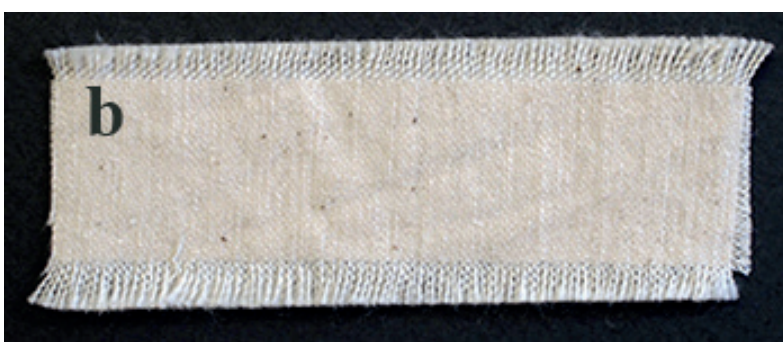

$M C(\%)=\frac{\left|M_{1}-M_{2}\right|}{M_{1}} \times 100$

where $\mathrm{MC}$ is the mass change (\%), $\mathrm{M}_{1}$ is the dry matter before incubation ( $\mathrm{g}$ ), and $\mathrm{M}_{2}$ is the dry matter after incubation $(\mathrm{g})$. It is to be noted that in the present study, it was preferred to use "mass change" instead of "mass loss" as it is customarily used in papers. The reason will be further discussed that an increase was observed in the weight of specimens exposed to the test fungus.

\section{TENSILE TEST PROCEDURE}

Tensile tests were carried out according to ASTM D-5035 standard specification by an Instron 5566 universal test machine (manufactured in the USA). The initial distance between the two jaws was fixed to $50 \mathrm{~mm}$ for specimens of all control, FE, and NWFE treatments. Loading speed was $40 \mathrm{~mm} / \mathrm{min}$.

\section{DENSITY FUNCTIONAL THEORY (DFT)}

OpenMX3.6 package (Majidi 2012, 2016) was utilized for density functional theory (DFT) to simulate the adsorption of NW on cellulose surface at molecule level (Taghiyari et al. 2016). The generalized gradient approximation (GGA) function with the Perdew-Burke-Ernzerhof (PBE) correction was carried out to describe the exchange-correlation energy functional (Perdew et al. 1996). The van der Waals (vdW) interactions were included by DFT-D2 approach proposed by Grimme (2006). 


\section{STATISTICAL ANALYSIS}

Statistical analysis was conducted using SAS software program, version 9.2 (2009). Two-way analysis of variance (ANOVA) was performed to discern significant difference at the $95 \%$ level of confidence. Grouping was then made between treatments, using the Duncan's multiple range test. Hierarchical cluster analysis, including dendrogram and using Ward methods with squared Euclidean distance intervals, was carried out by SPSS/18 (2010) (Ada 2013). Fitted-line plots were made by Minitab software, version 16.2.2 (2010).

\section{RESULTS AND DISCUSSION}

Weight measurements before and after NWimpregnation demonstrated that NW-uptake values were 30 and $25 \mathrm{~g} . \mathrm{m}^{-2}$ in warp and wept specimens, respectively. Visual observation demonstrated that after three months of exposure to Aspergillus nigra, mycelia of the fungus nearly covered all parts of the cotton specimen in the Petri dish (Fig. 2a). However, NW-impregnated specimens illustrated some resistance to the growth of fungus hyphae (Fig. 2b); the fact that the adjacent Sabouraud's agar were completely covered by mycellium of the fungus implied that wollastonite practically hindered the growth of fungus on the NWimpregnated specimens.

The results of the weight measurements before and after being exposed to A. nigra demonstrated that all cotton textile specimens were increased in weight after the exposure to the fungus. This increase in weight was due to the penetration of mycelium of the fungus into the texture of cotton textile; that is, mycelium was initially fed with Sabouraud's agar and grew into cotton texture. In the control specimens and after the initial stage when Sabouraud's agar was used up, mycelium also consumed the cotton textile; however, the amount used Sabouraud's agar was higher than cotton texture, leading to the increase in weight.
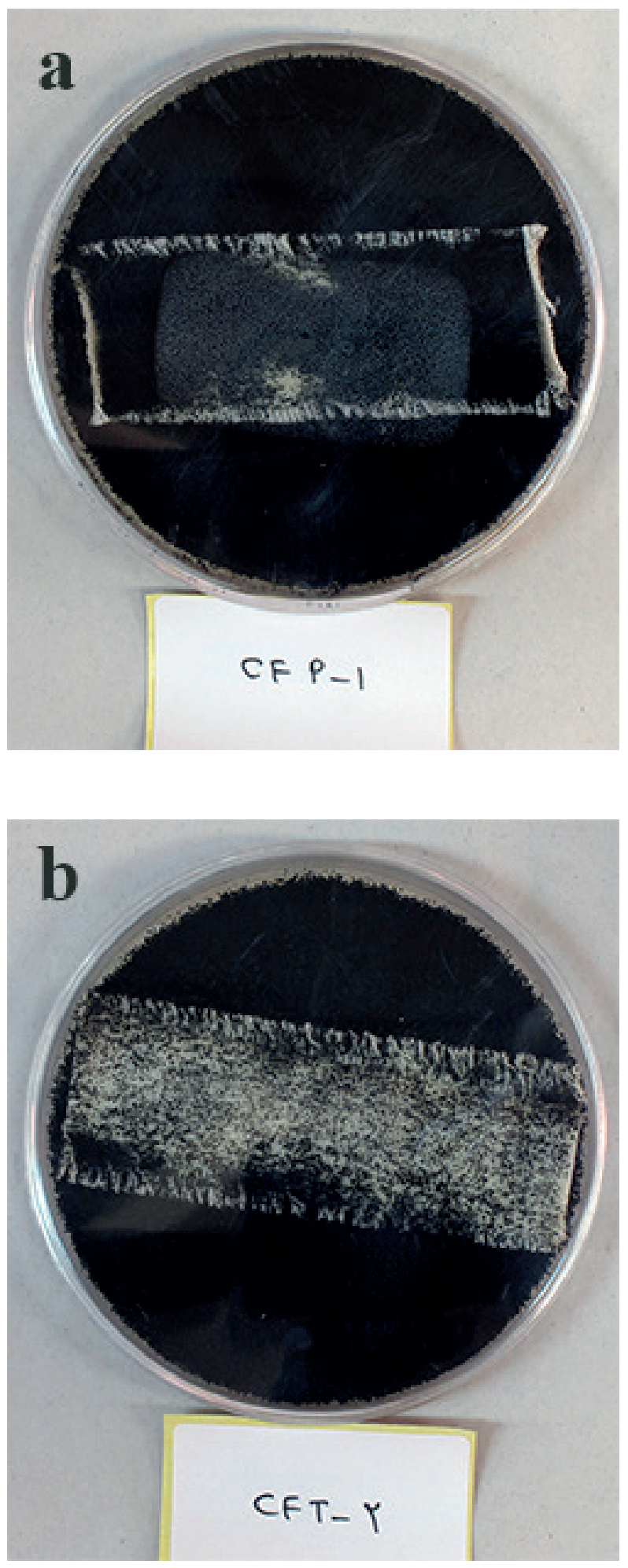

Figure 2 - Visual observation of the control (a) and NWimpregnated (b) specimens after three months of exposure to A. nigra in Petri dish. 
In this regard, specimens in wept directions had higher weight changes both in the control and NWimpregnated specimens in comparison to warp specimens (Fig. 3a). The highest and lowest weight changes occurred in the control specimens in wept direction (4.37\%) and NW-impregnated specimens in the warp direction $(0.9 \%)$, respectively. Impregnation of the cotton specimens with wollastonite significantly decreased weight changes in both directions. This showed the hindering impact of wollastonite on the growth and deterioration of cotton ingredients. Similar hindering effects were previously reported on other cellulose-based materials, like particleboard (Taghiyari et al. 2014a), medium-density fiberboard (Taghiyari et al. 2014b), solid wood species (Karimi et al. 2013), and even paper (Taghiyari et al. 2014c).

Control specimens in the warp direction and fungus-exposed specimens in wept direction had the highest (29.7 MPa) and the lowest (16.2 MPa) tensile stresses, respectively (Fig. 3b). Maximum tensile stresses in warp direction of the cotton fabric were higher in all treatments. This indicated that threads in the longitudinal direction of cotton textile had higher loading capacity than in the wept direction. With due consideration to the fact that in practice, different fabrics should usually bear more loading in the longitudinal direction in comparison to the transverse direction, this seems logical. Exposure to A. niger resulted in significant loss in tensile stress values in both warp and wept directions. The percentage of loss in warp and wept directions were $47 \%$ and $60 \%$, respectively. The amount of losses in the NW-impregnated specimens were significantly lower; only about $7 \%$ and $4 \%$ in the warp and wept specimens, respectively.

As to the tensile strain values, wept specimens demonstrated higher strain values in all treatments. The highest and lowest strains were found in the NW-impregnated fungusexposed specimens in wept direction $(28.7 \%)$ and fungus-exposed specimens in the warp direction
(16.7\%), respectively (Fig. 3c). Exposure to $A$. nigra significantly decreased strain values in both directions. However, exposure to A. nigra in the $\mathrm{NW}$-impregnated specimens did not result in any change in the strain values of either directions; the values even seemed to increase, though the increase was not statistically significant. This slight increase, and lack of evidence in decreasing values in tensile stress values (Fig. 3b), could be attributed to formation of extra bonds between cellulose between the compounds in cotton cloth and NW ingredients (Fig. 4) (Taghiyari et al. 2016). Density functional theory (DFT) demonstrated that the optimal adsorption distance and adsorption energy for NW of $1.7 \AA$ and $-6.6 \mathrm{eV}$, respectively. This rather large amount of energy is indicative of extra bonds formed between the Calcium atoms (in NW ingredients) and the Oxygen atoms (in the hydroxyl groups of the cellulose chains in cotton cloth) (Fig. 4) (Taghiyari et al. 2016). This eventually contributed to a higher tensile stain in NW-impregnated values; it also contributed to the slight decrease in the tensile stress values in the $\mathrm{NW}$-impregnated fungus-exposed specimens in comparison to the fungus-exposed specimens. The formation of similar bonds was the main cause in improved physical and mechanical properties of different cellulose-based composites reported in some previous scientific projects.

Cluster analysis based on the properties measured demonstrated that control specimens in both warp and wept directions were significantly clustered differently from those specimens exposed to A. nigra for three months (Fig. 5). However, the specimens that were impregnated with NW prior to fungus-exposure were closely clustered to the control treatments. This indicated that the hindering effects of NW on growth of the fungus were so effective that the overall properties of NWimpregnated specimens can be considered similar to those of the control specimens from a statistical point of view. It was therefore concluded that NW 

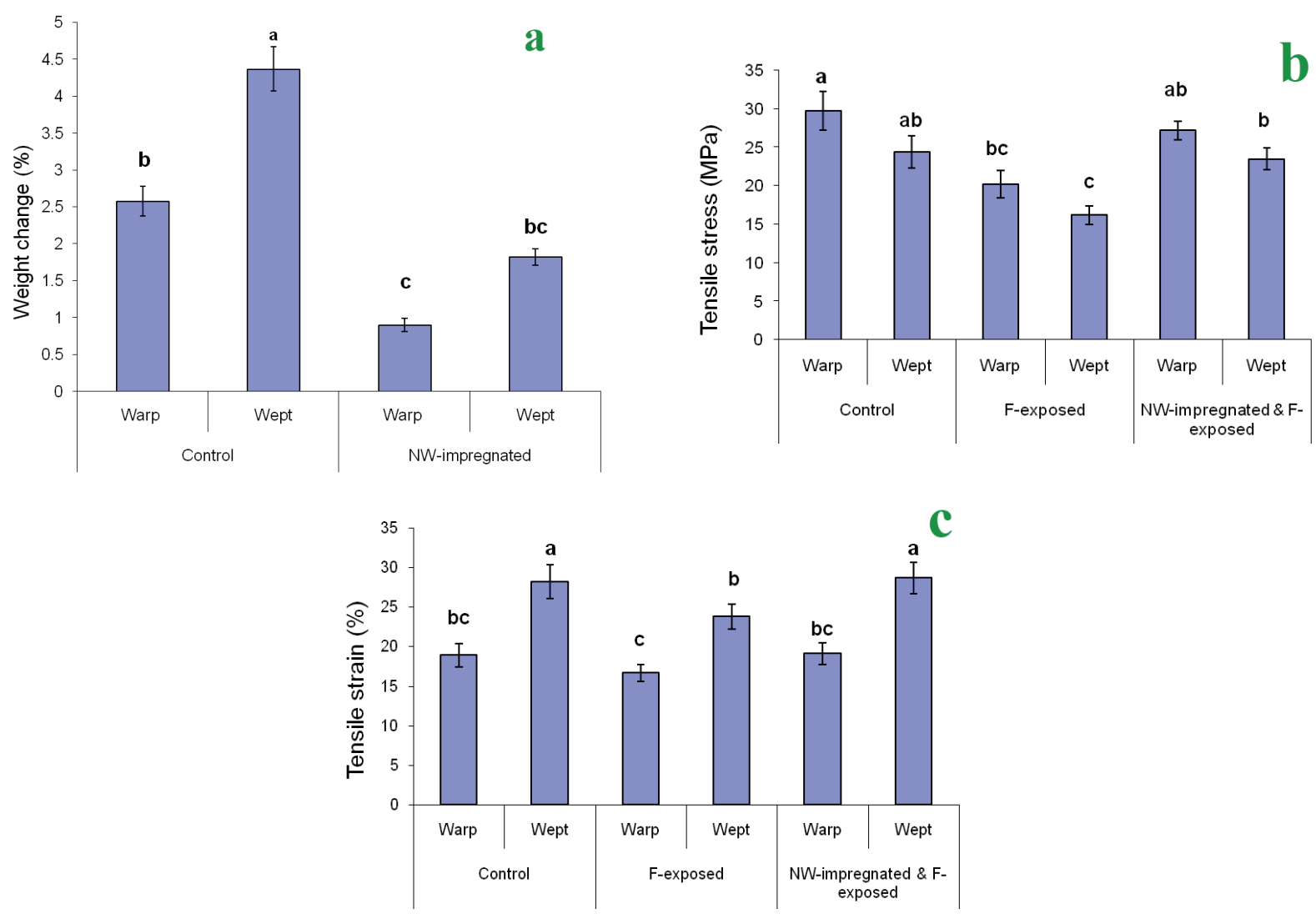

Figure 3 - Weight changes (a), tensile stress (b), and tensile stress (c) values in the control and NW-impregnated cotton cloth specimens in warp and wept directions, exposed to A. nigra for three months (capital letters on each column represent Duncan's groupings).

\section{1 layer of nanowolastone}

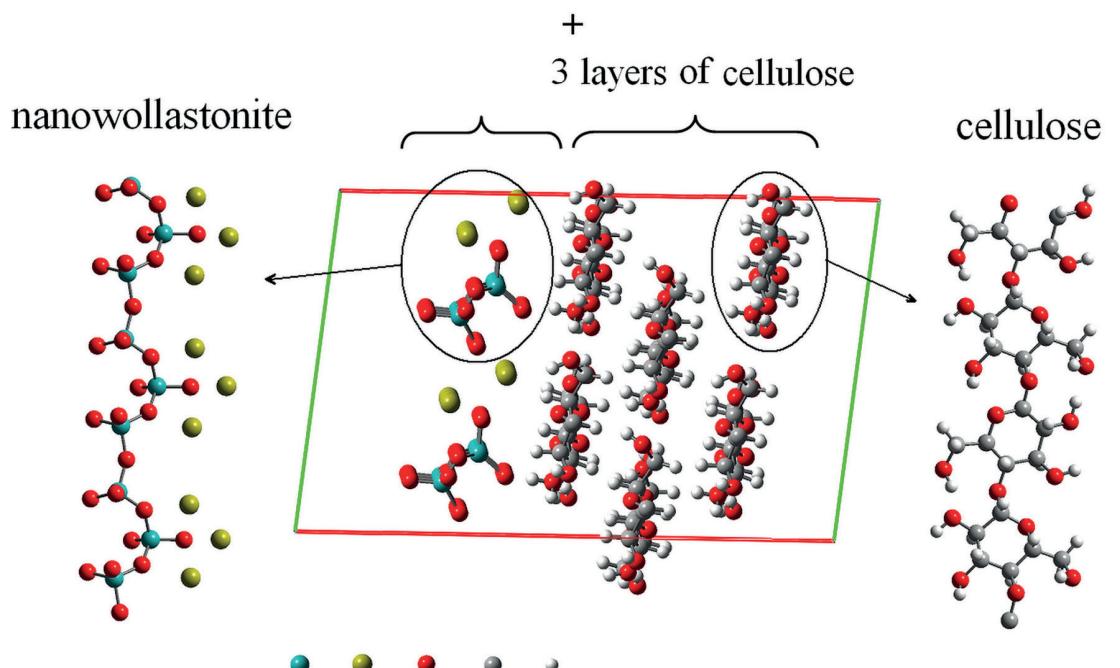

Si $\mathrm{Ca} \mathrm{O} \quad \mathrm{C} \quad \mathrm{H}$

Figure 4 - Schematic representation of bond formation between Calcium atoms of NW and Oxygen atoms of cell-wall cellulose chains (Taghiyari et al. 2016). 


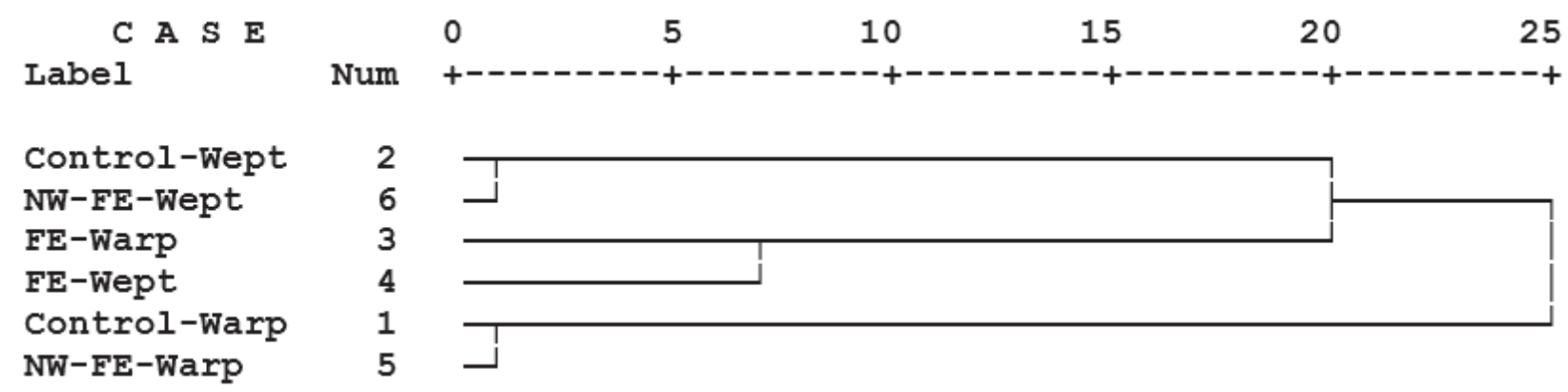

Figure 5 - Cluster analysis of the six treatments of cotton fabric specimens based on tensile strain and tensile stress values before and after exposure to Aspergillus niger fungus for three months ( $\mathrm{FE}=$ fungal-exposed; NW = nano-wollastonite).

can be considered an efficient material to hinder the growth of $A$. nigra on cotton fabrics in order to maintain its strength. As to the non-toxic nature of wollastonite to both human and wildlife, it is also a safe and hygiene material to be environmentally friendly be used for different fabrics. However, further studies should be carried out to practically find out the ultimate amount of wollastonite to be used for each fabric, its effects on other fungal species, and many other aspects of its utilization.

\section{CONCLUSIONS}

Aspergillus niger is a constant threat to works of art in museums around the world. Therefore, the present research project focused on the effects of exposure of $A$. niger for three months on cotton textile in warp and wept directions. Nano-wollastonite (NW) was used to find out its protective effects on the growth and activities of the fungus. The results were indicative of a significant loss in tensile stress, demonstrating its high activity on cotton. However, its activity was significantly limited by priorimpregnation of the specimens with NW. It was concluded that NW positively protect cotton textile against $A$. nigra; however, complementary studies should be committed to firmly make decision on the ultimate NW-content.

\section{ACKNOWLEDGMENTS}

The authors appreciate constant scientific support of Dr. Jack Norton (Retired, Horticulture and Forestry
Science, Queensland Department of Agriculture, Forestry and Fisheries, Australia).

\section{REFERENCES}

ABDEL-KAREEM O. 2010a. Monitoring, controlling and prevention of the fungal deterioration of textile artifacts in the museum of Jordanian Heritage. MAA Journal 10(2): 85-96.

ABDEL-KAREEM O. 2010b. Fungal deterioration of historical textiles and approaches for their control in Egypt. Morana RTD 7: 40-47.

ADA R. 2013. Cluster analysis and adaptation study for safflower genotypes. Bulg J Agric Sci 19(1): 103-109.

ALEXOPOULOS CJ, MIMS CW AND BLACKWELL MM. 1996. Introductory mycology, $4^{\text {th }}$ ed.,Wiley, New York, $880 \mathrm{p}$.

BARI E, SISTANI A, TAGHIYARI HR, MORRELL JJ AND CAPELLAZI J. 2017. Influence of Test Method on Biological Degradation of Bamboo-Plastic Composites by Fungi. Maderas Cienc Tecnol 19(4): 455-462.

BARI E, TAGHIYARI HR, SCHMIDT O, GHORBANI A AND AGHABABAEI H. 2015. Effects of nano-clay on biological resistance of wood-plastic composite against five wood-deteriorating fungi. Maderas Cienc Tecnol 17(1): 205-212.

ELAIEB MT, SHEL F, ELOUELLANI S, JANAH T, RAHOUTI M, THEVENON MF AND CANDELER K. 2017. Physical, mechanical and natural durability properties of wood from reforestation Pinus halepensis Mill. In the Mediterranean Basin. BFT J 331(1): 19-31.

GRACE S, IBACH RE, FAILLACE M, GNATOWSKI M, GLAESER JA AND HAIGHT J. 2017. Laboratory and exterior decay of wood-plastic composite boards: voids analysis and computed tomography. Wood Mater Sci Eng 12(5): 263-278.

GRIMME S. 2006. Semiempirical GGA-type density functional constructed with a long-range dispersion correction. J Comput Chem 27: 1787-1799. 
HUUSKONEN MS, JARVISALO J, KOSKINEN H, NICKELS J, RASANEN J AND ASP S. 1983a. Preliminary results from a cohort of workers exposed to wollastonite in a Finnish limestone quarry. Scandin J Work Environ Health 9(2): 169-175.

HUUSKONEN MS, TOSSAVAINEN A, KOSKINEN H, ZITTING A, KORHONEN O, NICKELS J, KORHONEN K AND VAARANEN V. 1983b. Wollastonite exposure and lung fibrosis. Environ Res 30(2): 291-304.

KARIMI A, TAGHIYARI HR, FATTAHI A, KARIMI S, EBRAHIMI GH AND TARMIAN T. 2013. Effects of wollastonite nanofibers on biological durability of poplar wood (Populus nigra) against Trametes versicolor. BioResources 8: 4134-4141.

MAJIDI R. 2012. A biosensor for hydrogen peroxide detection based on electronic properties of carbon nanotubes. Mol Phy 111: 89-93.

MAJIDI R. 2016. Electronic properties of graphyne nanotubes filled with small fullerenes: A density functional theory study. J Comput Electron 15: 1263-1268.

MARESI G, OLIVEIRA LONGA CM AND TURCHETTI T. 2013. Brown rot on nuts of Castanea sativa Mill: An emerging disease and its causal agent. iForest 6: 294-301.

MAXIM LD AND MCCONNEL EE. 2005. A review of the toxicology and epidemiology of wollastonite. Inhalation Toxicol 17(9): 451-466.

MORAIS R, CUNHA M, SANTANA G AND PAES JB. 2018. Dendrological Characterization as Inspection Resources of Caatinga Wood Market. Floresta Ambient 25(3): e20170813.

PERDEW JP, BURKE K AND ERNZERHOF M. 1996. Generalized Gradient Approximation Made Simple. Phys Rev Lett 77(18): 3865-3868.

PETHIG R. 2017. Review - Where is dielectrophoresis (DEP) going? J Electrochem Soc 164(5): B3049-B3055.

TUPCIAUSKAS R, IRBE I, JANBERGA A AND BUKSANS E. 2017. Moisture and decay resistanc and reaction to fire properties of self-binding fiberboard made from steamexploded grey alder wood. Wood Mater Sci Eng 12(2): 63-71.

SANDEEP N, SULOCHANA C AND KUMAR BR. 2017. Flow and heat transfer in MHD dusty nanofluid past a stretching/shrinking surface with non-uniform heat source/ sink. Walailak J Sci Technol 14(2): 117-140.
SCHMIDT O. 2006. Wood and tree fungi. Biology, damage, protection and use. Springer-Verlag, Berlin Heidelberg, $334 \mathrm{p}$.

SCHMIDT O. 2007. Indoor wood-decay basidiomycetes: damage, causal fungi, physiology, identification and characterization, prevention and control. Mycol Prog 6(4): 261-279.

SEEPHUEAK P, PREECHA C AND SEEPHUEAK W. 2018. Diversity of Macrofungi in oil palm (Elaeis guineensis Jacq.) plantation in Southern Thailand. Walailak J Sci Technol 15(3): 201-211.

TAGHIYARI HR, BARI E AND SCHMIDT O. 2014b. Effects of nanowollastonite on biological resistance of mediumdensity fiberboard against Antrodia vaillantii. Eur J Wood Prod 72(3): 399-406.

TAGHIYARI HR, BARI E, SCHMIDT O, TAJICK GHANBARY MA, KARIMI AAND TAHIR PMD. 2014a. Effects of nanowollastonite on biological resistance of particleboard made from wood chips and chicken feather against Antrodia vaillantii. Int Biodeterior Biodegrad 90: 93-98.

TAGHIYARI HR, KALANTARI A AND ERSHADLANGROUDI A. 2014c. Effects of wollastonite nanofibers on biological resistance of historical paper against Aspergillus niger. Lignocellulose 3(2): 111-118.

TAGHIYARI HR, KALANTARI A, GHORBANI M, BAVANEGHI F AND AKHTAI M. 2015. Effects of fungal exposure on air and liquid permeability of nanosilverand nanozincoxide-impregnated Paulownia wood. Int Biodeterior Biodegrad 105: 51-57.

TAGHIYARI HR, MAJIDI R AND JAHANGIRI A. 2016. Adsorption of nanowollastonite on cellulose surface: Effects on physical and mechanical properties of mediumdensity fiberboard (MDF). CERNE 22: 215-222.

TAGHIYARI HR, MOBINI K, SARVARI SAMADI Y, DOOSTI Z, KARIMI F, ASGHARI M, JAHANGIRI A AND NOURI P. 2013. Effects of nano-wollastonite on thermal conductivity coefficient of medium-density fiberboard. J Molec Nanotechnol 2: 1.

TANNY JB, VISAGIE CM, YILMAZ N AND SIFERT KA. 2017. Aspergillus subgenus Polypaecilum from the built environment. Studies in Mycology 88: 237-267. 